\title{
Distributed Generation Placement in Port Harcourt Network using Nodal Analysis
}

\author{
Ajabuego O. G. ${ }^{1}$ \\ Electrical Engineering Department, \\ University of Port Harcourt, \\ Port Harcourt, Rivers state, Nigeria
}

\author{
Uzoechi L. O. ${ }^{2}$ \\ Electrical \& Electronic Engineering, Department, \\ Federal University of Technology Owerri, \\ Nigeria
}

\begin{abstract}
This paper shows the placement of Distributed Generation (DG) and its impact in Port Harcourt Network. This is to counter the problem of instability and losses in the Network. The method considered for the proper placement of the DGs is the nodal analysis method. This method shows the weakest bus in the Network which is more advisable for placing the DGs. After the placement of a DG, another analysis is done to ascertain where the next DG should be placed considering that recently 13 completed DGs (ten 25MW and three 30MW) have been installed in Port Harcourt. The result gotten after simulating with MATLAB 7.9 software shows a progressive reduction in the voltage violations, real and reactive power losses down to when there is no voltage violated when 13 DGs are placed. The only difference is a slight increase in the real and reactive power losses from 12 to 13 DGs installations. From the result it can be concluded that proper placement of the DGs will effect a balance in the instability of the Port Harcourt Network.
\end{abstract}

Keyword: Distributed Generation, Voltage Stability, Nodal analysis, Port Harcourt, Eigenvalue

\section{INTRODUCTION}

Nigeria being a country with a very high population have not been able to stabilize its power system due to minimal generation supply. A recent statistics on use of generating sets in the country released by the Director-General of Centre for Management Development, Dr. Kabir Usman, revealed that about 60 million Nigerians spent N1.6 trillion on generators annually. The endemic power crisis came as a result of the inability of the existing plants to meet the ever increasing demand. The supply-demand gulf exist because of myriads of reasons: obsolete and dilapidated plants with $36 \%$ of installed capacity being over 20 years old; $48 \%$ are over 15 years old and $80 \%$ are over 10 years old [1]. Other factors include lack of and poor maintenance of existing plants and poor managerial efficiency. Though the country have hopes of installing more generating stations as time progresses using its natural resources, so many suggestions gave been given on a shorter solution using Distributed Generations (DGs). This is due to its limited complexity in installation or integration into a particular section of the Network, loss reduction, availability, etc.

Replacing fossil fuels with renewable energy is the ultimate goal, but because they currently account for 80 percent of global energy demand, it is not yet possible to do so and sustain even a basic standard of living. Indeed, although the volume of renewable energy is increasing at an enormous rate, it is still outstripped by rising energy demand [2].Though DGs will give a better and fast solution to better performance of the Network, it has its own limitations, which is more seen when the DGs are improperly placed. Improper placement of the DGs can result to so much losses in the system, voltage instability and investment wastage. These problems call for proper attention to the methods used to place the DGs in the Network to counter the problem faced in DG installation. Various methods have been proposed to counter most of this problem of DG installation, though more method are been proposed. For this paper, the method considered is the eigen value method. This method is considered more advantageous than the other methods due to its less complexity in deciding the best position to place the DGs considering the properties of the Buses. The method decides which Bus is more affected and the Bus which contributes more to its instability, which is considered as the weakest Bus.

\section{LITERATURE REVIEW}

Several papers reported on different techniques for DG allocation in radial distribution systems using probabilistic techniques [3], [4] However, because of the characteristics and constraints of mesh networks, it would be difficult to implement certain optimization strategies for DG allocation. Therefore, a probabilistic approach is proposed based on the relationship between customer demand and DG parameters (type, size, and location) [5], [6]. In the 1990s the voltage stability problem became an interesting topic for transmission networks and was extensively studied [7], [8]. Recently, with the advent of new DG technology, voltage stability studies have been extended to distribution networks [9]. In this paper the long-term voltage stability will be considered to reveal the system's ability to maintain steady voltage profiles following small disturbances experienced through continuous variations in load [10], [11].

\section{PORT HARCOURT NETWORK}

There are two numbers of transmission load centers in Port Hacourt complex (Port Harcourt mains and town) with a total installed capacity of $222.5 \mathrm{MVA}$ while the total peak loads are 106.5MW (day) and 127.7MW (night) respectively. These were obtained under system/generation limitations. Total availability from the independent power producers (IPP) or distributed generation averages 60MW daily that is supplied to Port Harcourt metropolis. This 
distributed generation (IPP) includes Omoku and TransAmadi and Eleme. They all have their challenges to overcome. Outside the generation limitations transmission constraint, and distribution inadequacies; the actual load demand should be in the vicinity of 361.9MW. There is presently, a gap of about $233.9 \mathrm{MW}$, which must be bridged.

In Port Harcourt metropolis, the installation distribution capacity is $444.5 \mathrm{MVA}$ on $33 \mathrm{kV}$ which translates to $355.6 \mathrm{MW}$ at operating power factor (PF) of 0.8 . Of course, the $33 \mathrm{kV}$ and $11 \mathrm{kV}$ distribution networks have not yet attained a state of perfection.

\section{A DG Sizing and Placement}

The two major factors considered in placing DGs in a network are the percentage DG level and the percentage dispersion of the DGs in the network. The percentage DG level accounts for the amount of DG against the power demand,

$\% D G$ level $=\frac{P_{D G}}{P_{\text {load }}} \times 100 \%$

where $\mathrm{P}_{\mathrm{DG}}$ is the power supply from the DG unit while $\mathrm{P}_{\text {load }}$ is the load demand of the area considered. For this thesis, the penetration level of the DGs was assumed to be total of 280MW which cannot be considered in percentage due to the supply from the grid and also no varying DG level considered.

The percentage dispersion of DGs accounts for how DGs are spread among buses depending on the number of buses or nodes.

$\% D G$ dispersion $=\frac{\text { Number of DG buses }}{\text { Number of laod buses }} \times 100 \%$

This is to say that when we have $100 \%$ dispersion means that all the DGs are attached to all buses. This scenario is applicable when only DGs are used to power the network and also for a smaller networks. For this thesis, it was assumed that due to the large bus network considered, the number of maximum bus attachment is only thirteen (13) buses or nodes as at against sixty nine (69) buses or nodes which is about $18.84 \%$ dispersion network. This is done to match the available DGs that can be achieved in Port Harcourt.

After the candidate buses are selected, allocating DG units within the system requires investigation in terms of DG resources and their uncertainties. It also requires modeling the types of load and their criticality at each bus. In addition, placing the DG units in the most sensitive buses might violate the voltage limits or the capacity of the feeders, depending on the size of the DG units and the load demand of the system. Accordingly, this section proposes a method to place DG units with an objective of improving the voltage stability of the system. This study is demonstrated in fourteen scenarios;

a Scenario 1: The reference scenario, in which no DG units are connected to the system (base case). b Scenario 2: One DG is placed in one bus units and is connected to a single bus for all buses.

c Scenario 3: all DGs are shared to two buses (135MW and $145 \mathrm{MW}$ ) and are connected to different buses and the best is selected base on the voltage profile, losses and loading parameter

d Scenario 4: all DGs are shared to three buses (100MW, 100MW and 80MW) and are connected to different buses and the best is selected base on the voltage profile, losses and loading parameter.

e Scenario 5: all DGs are shared to four buses (75MW, $75 \mathrm{MW}, 75 \mathrm{MW}$ and $55 \mathrm{MW}$ ) and are connected to different buses and the best is selected base on the voltage profile, losses and loading parameter.

$f$ Scenario 6: all DGs are shared to five buses (60MW, $60 \mathrm{MW}, 60 \mathrm{MW}, 50 \mathrm{MW}$ and $50 \mathrm{MW}$ ) and are connected to different buses and the best is selected base on the voltage profile, losses and loading parameter.

g Scenario 7: all DGs are shared to six buses (50MW, $50 M W, 50 M W, 50 M W, 50 M W$ and 30MW) and are connected to different buses and the best is selected base on the voltage profile, losses and loading parameter..

$h \quad$ Scenario 8: all DGs are shared to seven buses (four $50 M W$, one 30MW and two 25MW) and are connected to different buses and the best is selected base on the voltage profile, losses and loading parameter.

i Scenario 9: all DGs are shared to eight buses (three $50 M W$, one 30MW and four 25MW) and are connected to different buses and the best is selected base on the voltage profile, losses and loading parameter.

j Scenario 10: all DGs are shared to nine buses (two $50 M W$, one 30MW and six 25MW) and are connected to different buses and the best is selected base on the voltage profile, losses and loading parameter.

k Scenario 11: all DGs are shared to ten buses (one $50 M W$, one $30 M W$ and eight 25MW) and are connected to different buses and the best is selected base on the voltage profile, losses and loading parameter.

l Scenario 12: all DGs are shared to eleven buses (one $30 \mathrm{MW}$ and ten 25MW) and are connected to different buses and the best is selected base on the voltage profile, losses and loading parameter.

$m$ Scenario 13: all DGs are shared to twelve buses (ten $25 \mathrm{MW}$, one 20MW and one 10MW) and are connected to different buses and the best is selected base on the voltage profile, losses and loading parameter.

$n \quad$ Scenario 14: all DGs are shared to thirteen buses (ten $25 \mathrm{MW}$ and three 10MW) and are connected to different buses and the best is selected base on the voltage profile, losses and loading parameter

\section{B Modal analysis}

Modal analysis determines how sensitive the buses to stability under a disturbance by computing the Eigen values and associated Eigenvectors of the reduced Jacobean matrix gotten from load flow. This analysis was also necessary to decide where the next DG should be placed. The lowest $J_{R}$ indicates the bus that is more pruned 
to voltage instability. Negative real $J_{R}$ at any load point indicates that the system is unstable. Stability is ascertained when all the real $\mathrm{J}_{\mathrm{R}}$ are positive. $\boldsymbol{J}_{\boldsymbol{R}}=\frac{\Delta \boldsymbol{Q}}{\Delta \boldsymbol{V}}$

The reduced jacobian matrix represents a linearized relationship between the increment changes in bus voltage $(\Delta \mathrm{V})$ and the changes in reactive power $(\Delta \mathrm{Q})$. The load bus which participate more to contribute instability is of utmost importance and can be expressed as

$\Delta V=\sum_{i} \frac{\phi_{i} \xi_{i}}{\lambda_{i}} \Delta Q$

Where, $\Phi_{\mathrm{i}}=\mathrm{i}^{\text {th }}$ right column vector $\xi_{\mathrm{i}}=\mathrm{i}^{\text {th }}$ row left eigenvector $\lambda_{\mathrm{i}}=\mathrm{i}^{\text {th }}$ eigenvalue

\section{RESULTS AND DISCUSSION}

The results for the load flow and eigenvalue analysis was gotten using MATLAB 7.9 software showing the voltage profile, real and reactive power losses and weakest Bus.

Table 1: Voltage stability analysis results

\begin{tabular}{|c|c|c|c|c|}
\hline $\begin{array}{c}\text { Number } \\
\text { of DGs }\end{array}$ & $\begin{array}{c}\text { Voltage } \\
\text { violation }\end{array}$ & $\begin{array}{c}\text { Real power } \\
\text { losses }\end{array}$ & $\begin{array}{c}\text { Reactive } \\
\text { power } \\
\text { losses }\end{array}$ & $\begin{array}{c}\text { Weakest } \\
\text { Bus }\end{array}$ \\
\hline No DG & 66 & 0.24811 & 3.4278 & 31 \\
\hline 1 & 65 & 0.2021 & 3.0234 & 64 \\
\hline 2 & 60 & 0.19871 & 2.914 & 59 \\
\hline 3 & 54 & 0.18658 & 2.6627 & 19 \\
\hline 4 & 50 & 0.15049 & 2.0678 & 12 \\
\hline 5 & 37 & 0.12916 & 1.7143 & 11 \\
\hline 6 & 25 & 0.10667 & 1.3618 & 13 \\
\hline 7 & 15 & 0.0819 & 1.0411 & 14 \\
\hline 8 & 9 & 0.06445 & 0.80931 & 3 \\
\hline 9 & 8 & 0.06165 & 0.75862 & 8 \\
\hline 10 & 4 & 0.05706 & 0.66731 & 25 \\
\hline 11 & 2 & 0.0482 & 0.51023 & 34 \\
\hline 12 & 1 & 0.0432 & 0.50939 & 63 \\
\hline 13 & 0 & 0.0448 & 0.58054 & 46 \\
\hline
\end{tabular}

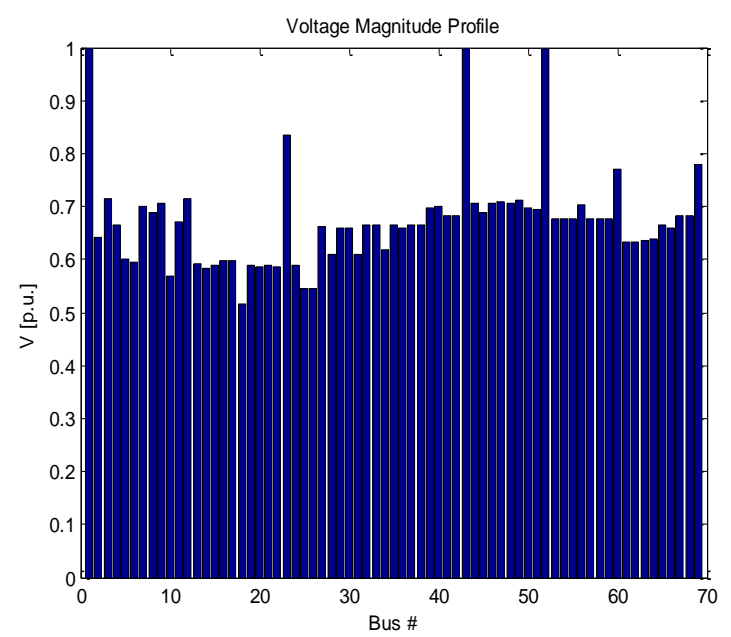

Fig. 1: Voltage profile without DG

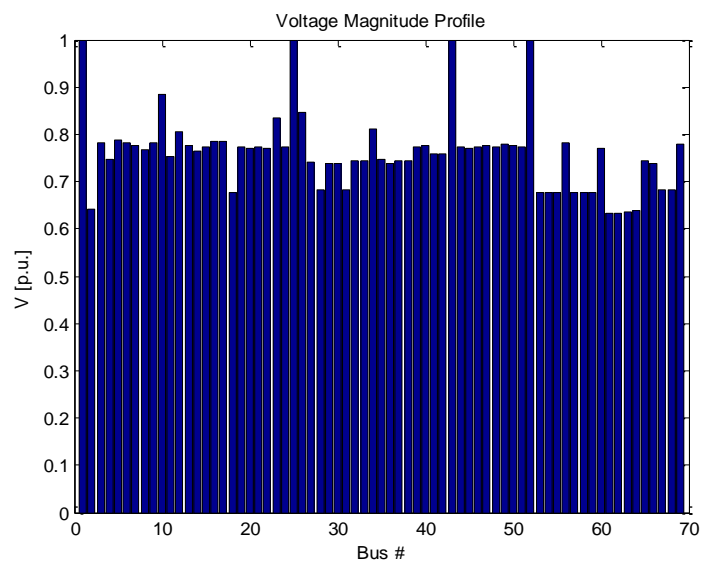

Fig. 2: Voltage profile with Single DG

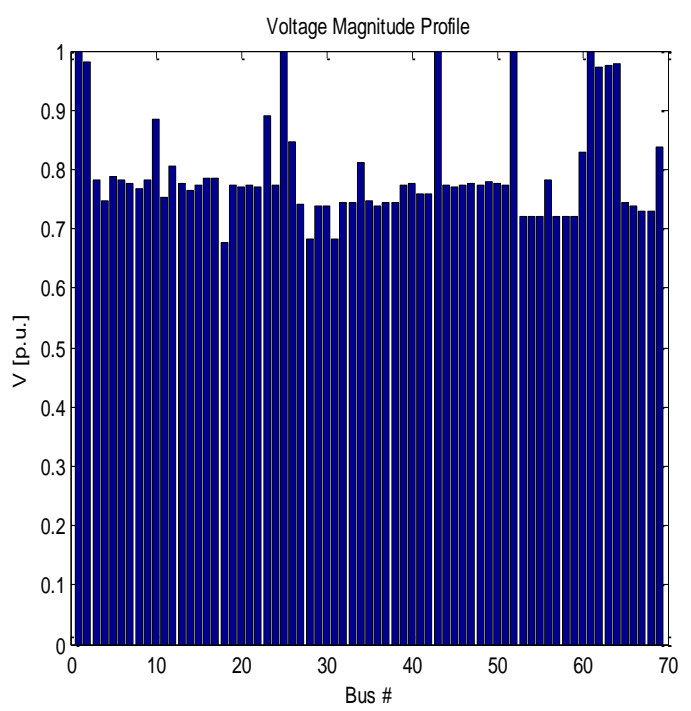

Fig. 3: Voltage profile with 2 DGs

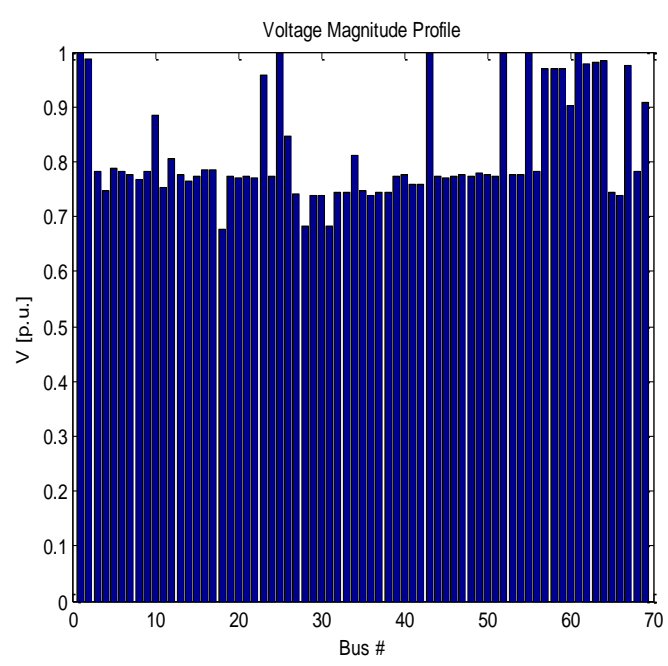

Fig. 4: Voltage profile with 3 DGs 


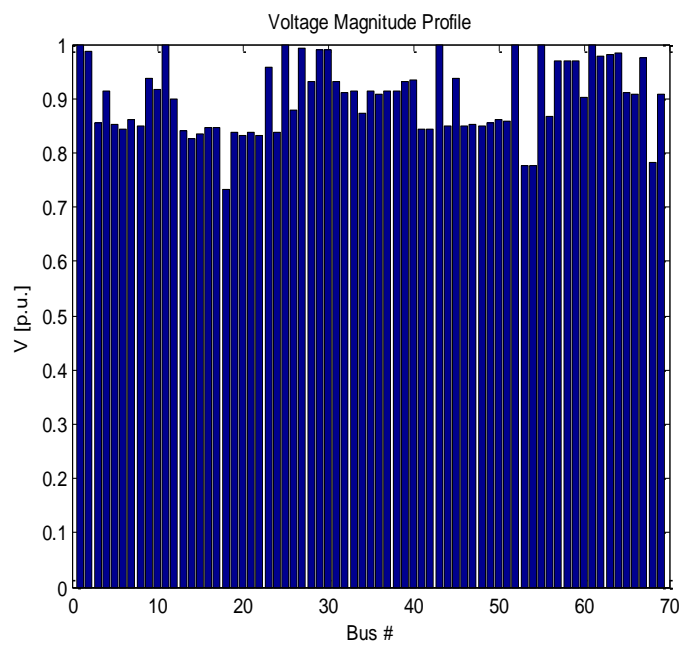

Fig. 5: Voltage profile with 4 DGs

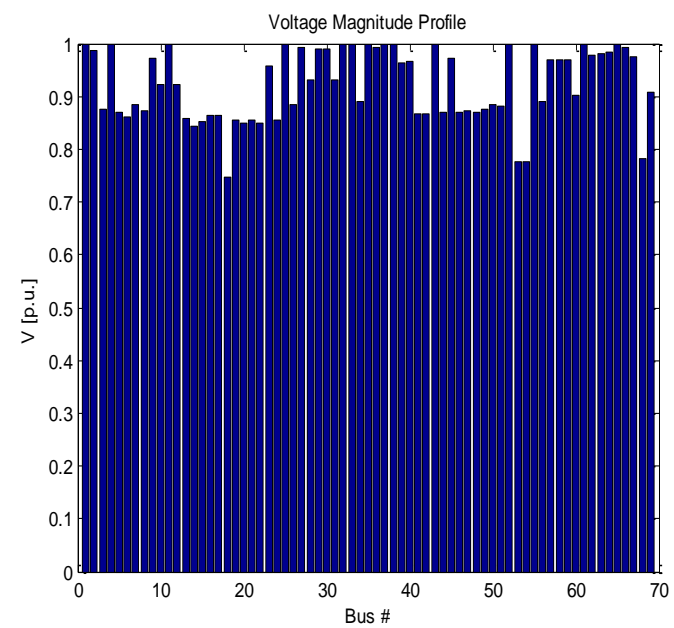

Fig. 6: Voltage profile with 5 DGs

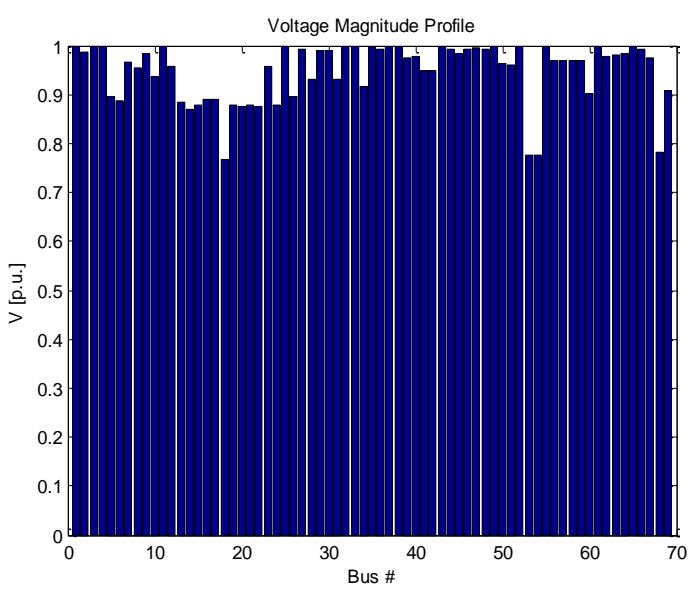

Fig. 7: Voltage profile with 6 DGs

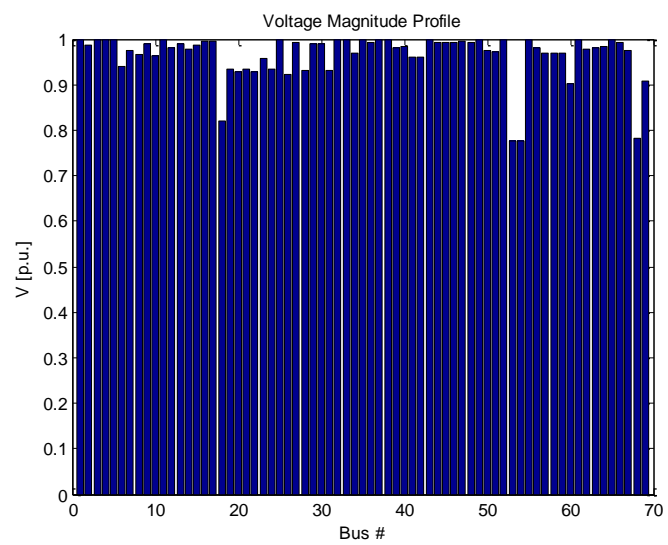

Fig. 8: Voltage profile with 7 DGs

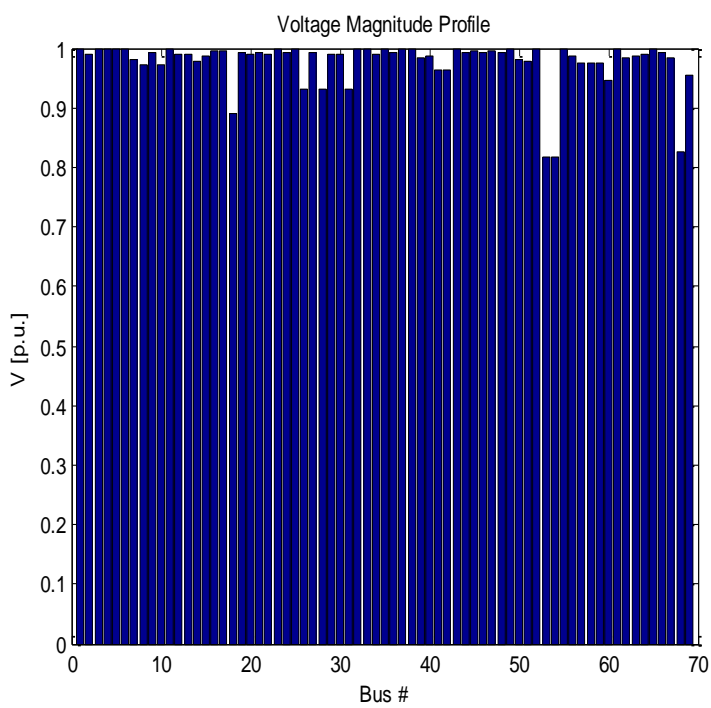

Fig. 9: Voltage profile with 8 DGs

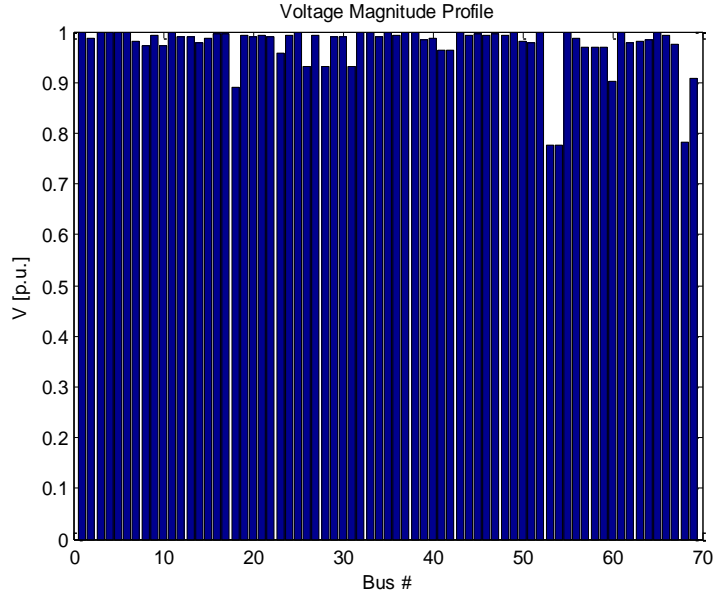

Fig. 10: Voltage profile with 9 DGs 


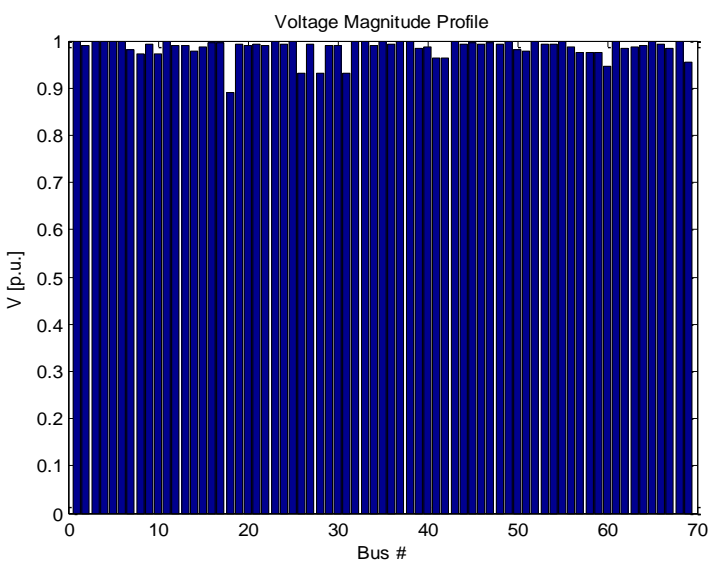

Fig. 11: Voltage profile with 10 DGs Voltage Magnitude Profile

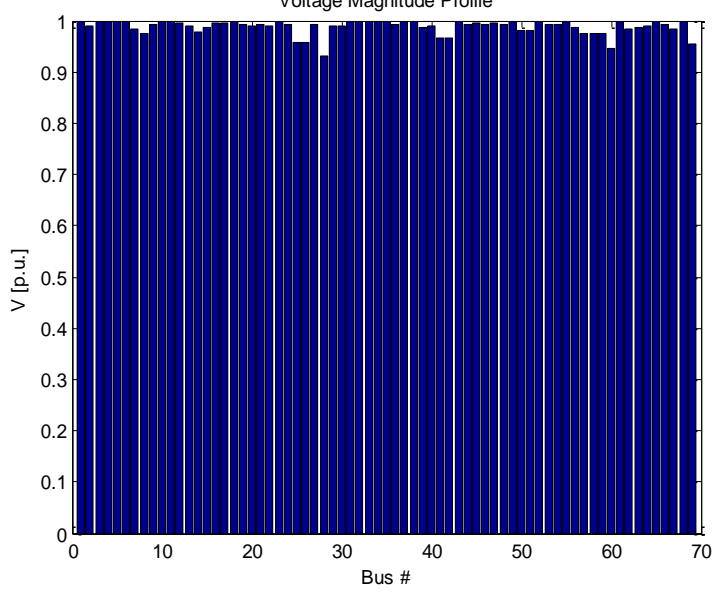

Fig. 12: Voltage profile with 11 DGs

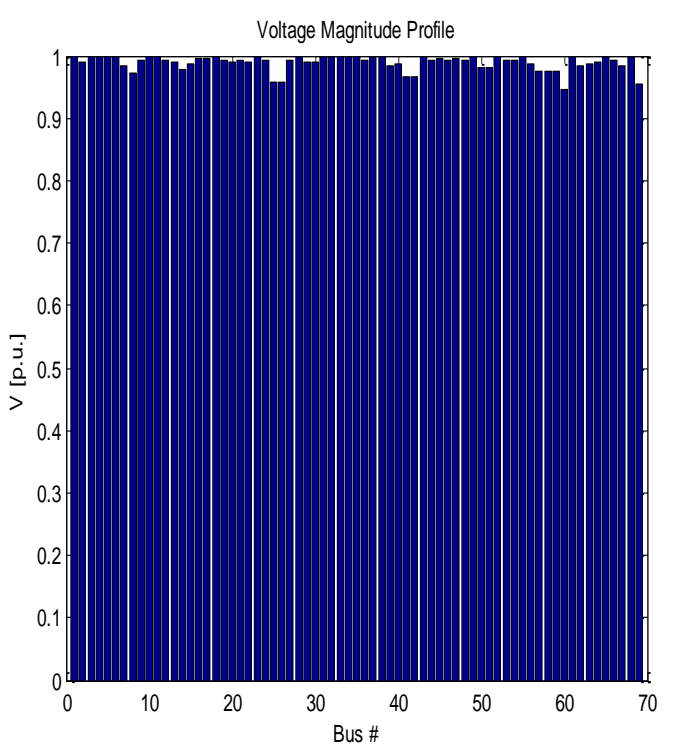

Fig. 13: Voltage profile with 12 DGs

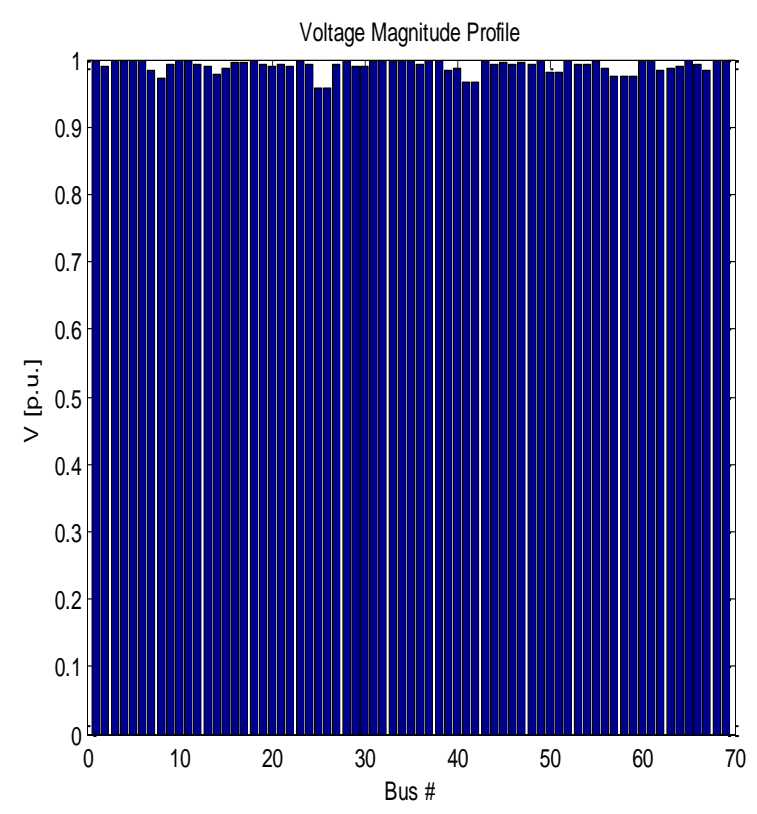

Fig. 14: Voltage profile with 13 DGs

\section{$\mathrm{V} \quad$ RESULT DISCUSSION}

From the result gotten, it is clear that there is so much voltage violations (i.e. 66 Buses) when no DG was added. Also, so much losses were incurred of about $2.14811 \mathrm{pu}$ real power loss and $3.4278 \mathrm{pu}$ for reactive power loss when DG was not added as seen in Table 1. At the inclusion of DGs, base on the available DGs, a drastic reduction in the voltage violation as seen in Figures 1-13, real and reactive power losses. There was no voltage violated at the inclusion of 13 DGs with total size of $230 \mathrm{MW}$. The best real and reactive power loss is seen at the introduction of 12 DGs (i.e. 0.0432pu real power loss and 0.50939pu reactive power loss), which gave $97.99 \%$ improvement for real power loss, 85.13 improvement for reactive power loss and $100 \%$ improvement for voltage violation as at when DG was not added.

\section{CONCLUSION}

The research thoroughly investigates the placement of DGs in the Port Harcourt Network. The DG placements considered in this work have proven to be one of the best method to use in allocating DGs to a Network. From the simulation, DG can easily be attached to the weakest Bus for optimal performance. This is seen in the drastic improvement in the voltage profile, real and reactive power losses. The voltage profile as compared to when DG was not added gave $100 \%$ improvement for the best performance attaining stability with no voltage violation when 13 DGs were added

\section{REFERENCES}

[1] A.F Adenikinju, (2003) Electric Infrastructure failures in Nigeria: A survey based analysis of the costs and adjustment responses. Retrieved April, 2009. www.sciencedirect.com/science

[2] L.Lawal, (2013). "Nigeria: A case Study in Power Shortages". International Journal of Economy, Management and Social Sciences 2(6), Pages: 410-418 
[3] Y.M. Atwa, and E.F. El-Saadany,. (2011). "Adequacy Evaluation of Distribution System Including Wind/Solar DG During Different Modes of Operation," IEEE Transactions on Power systems, vol. 26, num. 4, pp. 1945-1952.

[4] P. Dehghanian, S.H. Hosseini, M. Moeini-Aghtaie, and S. Arabali, (2013). “Optimal Siting of DG Units in Power Systems form a Probabilistic Multi-Objective Optimization Perspective”, International Journal of Electrical Power and Energy Systems, vol.51, pp.14-26.

[5] X.Chen, X. and W. Gao, (2008). "Effects of distributed generation on power loss, loadability and stability," in Proc. IEEE Southeastcon, pp. 468-473.

[6] Y. XU. Z Chen, and J. Ostergaard, (2009).“Control mechanism and security region for intentional islanding transition," in Proc. IEEE Power and Energy Society General Meeting, 2009, pp. 1-6.

[7] C. W. Taylor, (1994). "Power System Voltage Stability", McGraw-Hill, Inc.

[8] P. Kundur, (1994). Power System Stability and Control, McGraw-Hill, Inc.

[9] R.S. Abri, E.F. El-Saadany, and Y.M Atwa, (2013) "Optimal placement and sizing method to improve the voltage stability margin in a distribution system using distributed generation," IEEE Trans. Power Systems, vol. 28, no. 1, pp. 326-334.

[10] B.H. Lee, and Lee, K. Y. (1993)."Dynamic and static voltage stability enhancement of power systems," IEEE Trans. Power Syst., vol. 8, no. 1, pp. 231-238.

[11] V.Ajjarapu, . and C. Christy,. (1992)."The continuation power flow: A tool for steady state voltage stability analysis," IEEE Trans. Power Syst., Vol. 7, No. 1, pp. 416-423. 